meet before every opening day to negotiate a fixed price for the catch and a contribution per $\mathrm{kg}$ of octopus, to cover the committee's operating costs and to make a contribution to identified village development projects.

Since the workshop in September 2017 there have been a total of six openings following temporary closures across the three villages supported. At all opening days the fishers' committees collectively bargained fixed prices with local buyers. Opening day prices increased compared to prices observed on normal fishing days. In addition, the buyers' contribution for conservation now partially covers the committees' operating costs. This could be a sustainable finance model for longer term community-based conservation.

A further significant benefit of the market development work is the strengthening of the village fishers' committee as a village institution responsible for the sustainable use of marine resources. Community members have delegated the committee to negotiate on their behalf, and higher prices reinforce the roles and benefits of this village institution, with the community now seeking active participation to increase transparency and accountability.

KIRAN MOHANAN and TANGUY NICOLAS Fauna \& Flora
International, Cambridge, UK
E-mail kiran.mohanan@fauna-flora.org

LORNA SLADE Mwambao Coastal Community Network, Stone town, Zanzibar, Tanzania

\section{Fauna \& Flora International expands strategy on marine plastics}

In June 2018 the UK's microbead ban came fully into force. The legislation developed by the UK Department for Environment, Fisheries and Rural Affairs marked the culmination of efforts by a coalition of NGOs, including Fauna \& Flora International (FFI), to address this source of avoidable microplastic pollution across the UK.

Used in a wide range of consumer products, including rinse-off toiletries such as facial scrubs, shaving products and toothpastes, microbeads (microplastic particles) are known to pass through wastewater treatment and enter the sea, where their size makes them immediately available to filter feeders (Tanaka \& Takada, 2016, Scientific Reports, 6,34351 ). FFI has engaged with this issue since 2009 , has compiled a database of $>1,500$ products to identify those containing microplastic ingredients and developed a set of guidelines to inform robust national bans and corporate policies on microbeads (https://api.faunaflora.org/wp-content/uploads/2018/o6/Microbeads-GuidanceDocument.pdf). These guidelines were used to inform the UK microbead legislation and are now being shared more widely, with a simplified briefing for their use being made available for other countries or companies considering such action.

On the basis of this achievement, and in line with the current upsurge in public and political interest in plastic pollution, FFI has launched a revised and expanded strategy to guide its ongoing work to tackle marine plastics. FFI recognizes the many threats plastic poses to marine life (including entanglement in abandoned fishing gear and the impact of ingestion of plastic pieces) and also has specific concerns about the potential for microplastic pollution to introduce hazardous substances into the marine food chain.

This new strategy has a stronger focus on FFI's international role in supporting the development of local initiatives to target marine plastics, particularly in countries where plastic pollution is most problematic. We recognize that management of plastic waste presents specific challenges in the context of emerging and developing economies, and are looking for solutions to deal with the consequences for ocean pollution and human health through reduction at source rather than just focusing on clean-ups. Scoping work for interventions is under development in Cambodia, Indonesia, Honduras, Kenya and Belize. In addition, we are actively supporting the Commonwealth Clean Oceans Alliance (https://www.gov.uk/government/ news/commonwealth-unites-to-end-scourge-of-plastic), a group of Commonwealth nations working together to address plastic pollution, convened by the UK and Vanuatu. This provides a means for countries to share expertise, access resources where needed and develop joint commitments to act on plastics.

However, FFI also retains a strong focus on preventing direct sources of microplastic pollution (plastic particles reaching the ocean at sizes $<5 \mathrm{~mm}$, such as microbeads, plastic pellets and microplastic fibres), given concerns about the potential for microplastics to introduce hazardous substances (either additives or sorbed chemicals) into the marine food chain. We continue to address the loss of preproduction pellets (so-called nurdles) to the environment, and are advocating a supply chain approach to their management. This would ensure that pellets are well handled by all companies who use, transport or otherwise handle them, against recognized standards and with clear objective monitoring and reporting. This approach for tackling pellet loss was mentioned in this year's EU Plastic Strategy (https:// ec.europa.eu/commission/publications/legal-documents-plasticsstrategy-circular-economy_en), at recent OSPAR (Convention for the Protection of the Marine Environment of the North-East Atlantic) meetings, and in the Plastics Charter issued as part of the $2018 \mathrm{G} 7$ communiqué (https://g7.gc. ca/wp-content/uploads/2018/o6/OceanPlasticsCharter.pdf). We continue to work with other NGOs, the plastics industry, retailers, standards bodies, investors and government on this issue. We have also started to identify ways in which we can help address the emerging challenge of microplastic 
fibres polluting the marine environment, whether from synthetic clothing via washing machines or directly from ropes and nets used at sea.

Across our work, FFI aims to provide strong evidencebased advice on potential solutions to marine plastic pollution. Although FFI recognizes that plastic can have a vital role in global society (e.g. in healthcare and in some situations for providing access to safe water), we also advocate careful and thoughtful use of plastic, using it only where it is determined to be necessary and the best solution relative to alternative materials. We also disseminate key stories about marine plastics issues, particularly with an international flavour, through our @marine_plastics Twitter account.

Abigail Entwistle, Dilyana Mihaylova and Hazel Akester Fauna \& Flora International, Cambridge, UK

E-mail abigail.entwistle@fauna-flora.org

\section{Local community neutralizes traditional wolf traps and builds a stupa}

During May-June 2018 the Buddhist Chang pa pastoral people of Chushul village in the Indian Changthang neutralized four traditional pit traps used for trapping wolves Canis lupus and symbolically built a stupa (a Buddhist ritual structure) adjacent to one of the traps (Plate 1). This is a pioneering community-led initiative for large carnivore conservation.

The Chang pa community has traditionally used traps (locally called shang-dong, derived from shangku, wolf, and dong, trap) to trap and kill wolves in retaliation for livestock predation. These traps, typically built near villages or herder camps, comprise large pits $(3-4.5 \mathrm{~m}$ diameter, $2.5-3 \mathrm{~m}$ deep) with inverted funnel-shaped stone walls.

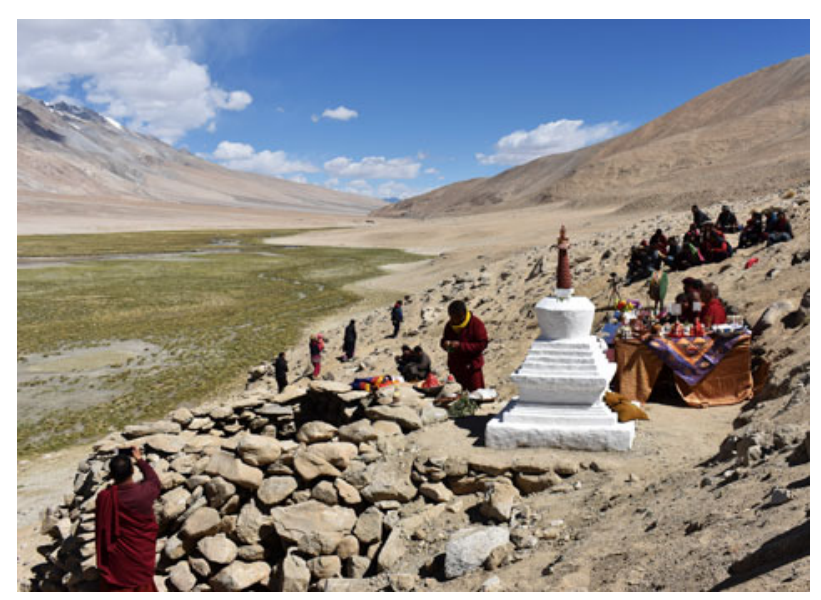

Plate 1 Inauguration ceremony for the stupa (a Buddhist ritual structure) built adjacent to one of the neutralized wolf traps in the Indian Changthang.
Bait of livestock remains attracts wolves but the funnel shaped walls prevent them from escaping. Typically the trapped wolves would be pelted to death with stones and the carcass then carried around neighbouring areas by the hunters, who would be rewarded by the villagers. Occasionally snow leopards become trapped, and are often killed.

Following 2 years of discussion between Chushul villagers and conservationists from the Nature Conservation Foundation and Snow Leopard Trust, the community agreed to dismantle the four existing wolf-traps in their area. To conserve their historical and cultural value, the traps were neutralized rather than destroyed. A stupa built adjacent to one of the traps was consecrated by His Eminence Bakula Rangdol Nyima Rinpoche, a revered Buddhist monk, on 14 June 2018, with support from the Leh district administration, Ladakh Autonomous Hill Development Council, Department of Wildlife Protection, Himalayan Cultural Heritage Foundation, and Chushul Youth and Gompa (Monastery) associations.

Conservation of large carnivores in multiple-use landscapes continues to be a challenge. The Tibetan Plateau and the Trans-Himalaya comprise 2.6 million $\mathrm{km}^{2}$ of high altitude, cold desert ecosystem, of which the north-west is known as the Changthang (Northern Plains). The mainstay of the nomadic peoples of Changthang, the Chang pa, is livestock grazing, especially cashmere (pashmina) goats. In the Indian Changthang $55 \%$ of households depend on cashmere production, producing c. $37,000 \mathrm{~kg}$ of cashmere annually.

The Changthang region also supports 13 species of wild carnivores, of which wolves are the most widespread. They are the main predator of livestock, accounting for up to $60 \%$ of total livestock depredation. Managing wolf depredation is challenging as they are highly mobile, with large home ranges.

The global demand for cashmere has resulted in overstocking of these rangelands, caused depletion of wild herbivore populations, and resulted in intensified conflicts as a result of livestock depredation by wolves and snow leopards (Berger et al., 2013, Conservation Biology, 27, 679-689). The conservation effort of the Chushul community is part of a larger initiative, working with herding communities to make cashmere production sustainable and conservation friendly. A certification system implemented by the Nature Conservation Foundation and the Snow Leopard Trust in partnership with the All Changthang Pashmina Growers Marketing Cooperative Society encourages and supports several sustainable livestock grazing practices: creation of village wildlife reserves, rotational grazing, management of carnivore-caused livestock damage through predator-proofing of livestock corrals and livestock insurance, and cessation of retaliatory killing of carnivores. Cashmere from partner herder communities implementing these practices is certified snow leopard friendly and attracts 